\title{
"Do we Need to Investigate Respiratory Virus in Hospitalized Infants with Suspected Pertussis?"
}

\author{
Sandra E. Vieira ${ }^{1 *}$, Angela E. Ferronato ${ }^{2}$ and Daniela Leite ${ }^{3}$ \\ ${ }^{1}$ Department of Pediatrics- Faculdade de Medicina da Universidade de São Paulo, Brasil \\ ${ }^{2}$ Department of Pediatrics, University Hospital/ Universidade de São Paulo, Brasil \\ ${ }^{3}$ Instituto Adolfo Lutz/ São Paulo, Coordinator of the National Reference Laboratory for Pertussis, Brasil
}

*Corresponding author: Sandra E. Vieira, Department of Pediatrics- Faculdade de Medicina da Universidade de São Paulo, Brasil, E-mail: sandra@hu.usp.br

Received date: March 03, 2016; Accepted date: May 12, 2016; Published date: May 16, 2016

Citation: Vieira SE, Ferronato AE, Leite D (2016) The Intracellular Signalling that Associated with Influenza a Virus Infection. Pediatric Infect Dis 1: 13. doi: $10.21767 / 2573-0282.100013$

Copyright: (c) 2016, Vieira SE, et al. This is an open-access article distributed under the terms of the Creative Commons Attribution License, which permits unrestricted use, distribution, and reproduction in any medium, provided the original author and source are credited.

Keywords: Bordetella pertussis; whooping cough; Respiratory virus; Bronchiolitis; Co-infection

\section{Introduction}

Respiratory virus (RV) and Bordetella pertussis (BP) are common etiological agents of respiratory infections in infants during the first year of life. Those infants younger than 6 months, still partially immunized for $B P$, are also the most susceptible to severe viral infections leading to hospitalization, such as in cases of bronchiolitis caused by respiratory syncytial virus $[1,2]$. Although some striking clinical characteristics of pertussis are common in older children and adults, in these infants the clinical picture may be less typical. Co-infection with RV and BP can also occur, due to co-circulation of these agents and the susceptibility of infants $[1,3,4]$.

In a previous retrospective study, the authors pointed to the need to investigate RV in infants with suspected pertussis [4]. In this short communication, preliminary results of a prospective cohort study that compares the characteristics of these different etiologies are presented. The results can contribute to strategies of prevention, diagnosis and treatment of respiratory infections in infants.

\section{Material and Methods}

The prospective study included all hospitalized infants less than one year of age with suspected pertussis, between June 2014 and December 2015. The criterion of inclusion to select pertussis suspected cases was based on the orientation of the São Paulo State Health Department. According to the health department the definition of suspected case of whooping cough is: "any person without other apparent cause and regardless of immunization status with dry cough for at least two weeks, followed by one of the following manifestations: paroxysmal cough, inspiratory winch and vomiting after coughing". We reduced to ten days or more of cough to increase the sensibility for inclusion. Those children that have used macrolides or other antibiotics and viral agents prior to diagnoses were excluded. The Ethics Committee of the Hospital approved this study.

Following a standardized protocol, we collated demographic, clinical, laboratory, and outcome data. According to the service routine, all these patients had nasal swab for BP identification (culture techniques and polymerase chain reaction (PCR), standardized at the Adolfo Lutz Institute [5]) and nasopharyngeal secretions for RV identification (indirect immunofluorescence assay) collected at admission.

The patients were divided into two groups, with single agent detection, for comparison: the group with pertussis (BP) and the group with respiratory virus (RV). The clinical/laboratory characteristics and the severity of infection and treatment were compared.

\section{Statistical analyses}

A convenience sample was analyzed. For descriptive analysis, the categorical variables are presented as total numbers and percentages and continuous variables as averages and standard deviation. Comparative analysis of categorical variables using the chi-square test and the $t$ test, considering significant $p=0.05$ was performed. The variables with $p<0.20$ in the univariate analysis were subjected to multivariate analysis model. The positive and negative predictive values for outcomes "BP infection" and "RV infection" were calculated.

\section{Results}

We reported 74 suspected cases of whooping cough between June 2014 and December 2015. During this period, 59 children were included in the study, according to the inclusion criteria. Two cases were excluded due to use of macrolide prior to diagnosis. There was a loss of 7 patients, because collecting BP test and RV test were not possible. Fifty patients were analyzed: 14 patients presented positive BP and 13 presented positive viral test (10 respiratory syncytial virus, 2 parainfluenza- 3 and 1 influenza), all of them as single infections. Three samples 
presented simultaneous detection of BP and RV (respiratory syncytial virus, parainfluenza virus and adenovirus); therefore co-detection with RV occurred in $17.6 \%$ cases of laboratory confirmed pertussis. In 20 patients (38\%) no etiologic agent could be identified. The clinical, demographic data and comparative analysis are presented in Tables 1-3. All infants were born at term and showed no comorbidities.

Table 1: Descriptive analysis of 50 infants with suspected pertussis, *Cell count in peripheral blood; **Pulse oxymetry; $\mathrm{BP}=$ Bordetella pertussis; VR=Respiratory virus; ${ }^{* * *}$ All doses of vaccines recommended for age according to Brazilian Immunization Program.

\begin{tabular}{|c|c|}
\hline \multicolumn{2}{|c|}{ CLINICAL AND DEMOGRAPHIC DATA } \\
\hline & $\mathrm{N}(\%)$ \\
\hline Male & $30(60)$ \\
\hline Cyanosis & $42(84)$ \\
\hline Vomiting & $39(78)$ \\
\hline Dyspnea & $36(72)$ \\
\hline Wheezing & $22(44)$ \\
\hline Apnea & $18(36)$ \\
\hline Fever & $17(34)$ \\
\hline Inspiratory whoop & $16(32)$ \\
\hline Anorexia & $10(20)$ \\
\hline \multicolumn{2}{|l|}{ mean (standard deviation) } \\
\hline Age - days & $93.9(60.3)$ \\
\hline Leukocytes $^{*}\left(\mathrm{n} / \mathrm{mm}^{3}\right)$ & $19750(21706)$ \\
\hline Lymphocytes ${ }^{*}\left(\mathrm{n} / \mathrm{mm}^{3}\right)$ & $9479(8340)$ \\
\hline \multicolumn{2}{|l|}{ BACKGROUND } \\
\hline & $\mathrm{N}(\%)$ \\
\hline Contact with smokers & $18(36)$ \\
\hline Updated Immunization *** & $25(50)$ \\
\hline Maternal BP immunization & $02(04)$ \\
\hline Nursery & $02(04)$ \\
\hline Breast-feeding & $35(70)$ \\
\hline \multicolumn{2}{|l|}{ mean (standard deviation) } \\
\hline Number of people at home & $4.3(+/-1.5)$ \\
\hline Number of brothers & $1.5(+/-1.4)$ \\
\hline \multicolumn{2}{|c|}{ THERAPEUTIC AND OUTCOME } \\
\hline & $N(\%)$ \\
\hline Intensive care unit & $14(28)$ \\
\hline Oxygen therapy & $42(84)$ \\
\hline Bronchodilator & $11(22)$ \\
\hline Corticosteroid & $05(10)$ \\
\hline
\end{tabular}

\begin{tabular}{|c|c|}
\hline Antibiotics & $49(98)$ \\
\hline \multicolumn{2}{|l|}{ mean (standard deviation) } \\
\hline Length of oxygen therapy (days) & $4.6(+/-6.2)$ \\
\hline Length of stay (days) & $6.8(+/-7.3)$ \\
\hline Oximetry $\left(\mathrm{O}_{2} \%\right)^{* *}$ & $92.2(+/-6.1)$ \\
\hline \multicolumn{2}{|l|}{ ETIOLOGY } \\
\hline & $\mathrm{N}(\%)$ \\
\hline $\mathrm{BP}$ & $14(28)$ \\
\hline $\mathrm{RV}$ & $13(26)$ \\
\hline Co-detection $(\mathrm{BP}+\mathrm{RV})$ & $03(06)$ \\
\hline Undetermined & $20(40)$ \\
\hline
\end{tabular}

Table 2: Comparative analysis between the groups with infection by BP or VR, as single etiologic agent, ${ }^{*}$ Cell count in peripheral blood; ** Pulse oxymetry; $\mathrm{BP}=$ Bordetella pertussis; VR= Respiratory virus; ${ }^{* * *}$ All doses of vaccines recommended for age according to Brazilian Immunization Program.

\begin{tabular}{|c|c|c|c|}
\hline & $B P(n=14)$ & $R V(n=13)$ & $\begin{array}{l}\text { Univariate } \\
\text { analysis }\end{array}$ \\
\hline & \multicolumn{2}{|l|}{$N(\%)$} & $\mathrm{p}$ \\
\hline Male & $09(64)$ & $06(46)$ & \multirow{3}{*}{0.34} \\
\hline Masculino & $09(64)$ & $06(46)$ & \\
\hline Feminino & $05(36)$ & $07(54)$ & \\
\hline Cyanosis & $14(100)$ & $09(69)$ & 0.03 \\
\hline Vomiting & $12(86)$ & 09(69) & 0.30 \\
\hline Dispneia & $09(64)$ & $11(85)$ & 0.23 \\
\hline Wheezing & $02(14)$ & $10(77)$ & $<0.001$ \\
\hline Apnea & $05(36)$ & $05(38)$ & 0.88 \\
\hline Fever & $02(14)$ & $07(54)$ & 0.03 \\
\hline Inspiratory whoop & $04(29)$ & $03(23)$ & 0.74 \\
\hline Anorexia & $04(29)$ & $03(23)$ & 0.84 \\
\hline Age (days) & $68.1(31.3)$ & $95.2(34.8)$ & 0.04 \\
\hline Leukocytes* & $\begin{array}{l}27674 \\
(33250)\end{array}$ & 16260 (12499) & 0.26 \\
\hline \multirow[t]{2}{*}{ Lymphocytes ${ }^{*}$} & $10810(6920)$ & $8026(6444)$ & 0.30 \\
\hline & \multicolumn{2}{|l|}{$N(\%)$} & \\
\hline Contact with smokers & $04(29)$ & $05(39)$ & 0.48 \\
\hline $\begin{array}{l}\text { Updated } \\
\text { Immunization }^{* * *}\end{array}$ & $04(29)$ & $07(58)$ & 0.13 \\
\hline $\begin{array}{l}\text { Maternal } \\
\text { immunization }\end{array}$ & $00(00)$ & $01(7.7)$ & 0.29 \\
\hline Nursery & $00(00)$ & $00(00)$ & nsa \\
\hline Breast-feeding & $12(86)$ & $09(69)$ & 0.49 \\
\hline $\begin{array}{l}\text { Number of people at } \\
\text { home }\end{array}$ & $4.4(1.0)$ & $4.8(2.5)$ & 0.52 \\
\hline
\end{tabular}




\begin{tabular}{|l|l|l|l|}
\hline Number of brothers & $1.2(1.1)$ & $2.3(1.9)$ & 0.94 \\
\hline & $\mathrm{N}(\%)$ & \\
\hline Intensive care unit & $04(29)$ & $05(38)$ & 0.59 \\
\hline Oxygen therapy & $13(93)$ & $12(92)$ & 0.96 \\
\hline Bronchodilator & $01(7.1)$ & $04(31)$ & 0.09 \\
\hline Corticosteroid & $00(00)$ & $02(17)$ & 0.11 \\
\hline Antibiotics & $14(100)$ & $12(92)$ & 0.29 \\
\hline $\begin{array}{l}\text { Length of oxygen } \\
\text { therapy (days) }\end{array}$ & $5.4(5.9)$ & $6.5(8.3)$ & 0.67 \\
\hline Length of stay (days) & $7.9(7.9)$ & $8.5(9.0)$ & 0.85 \\
\hline Oximetry (O2 \%) & $93.5(6.8)$ & $90.4(6.8)$ & 0.26 \\
\hline
\end{tabular}

in infants with a clinical diagnosis of pertussis, especially those partially immunized for BP.

These preliminary results show similar prevalence of BP and $\mathrm{RV}$. It is possible that such proportions can be modified until the end of the inclusion period. In a previous retrospective study, conducted at the same institution, the authors showed prevalence of $44 \%$ of BP and $26 \%$ of RV [4]. We already can highlight the importance of viral etiology in such preliminary results. In fact, pertussis in partially immunized infants may be associated with less typical clinical picture, which makes the suspicion raised even in the absence of such characteristic signals [8-11]. Such behaviour increases the sensitivity of screening for pertussis however decreases its specificity. In this study, age was significantly lower in infants with whooping cough, which can be linked to their immunization status [8]. The average age of the infants with pertussis was about 2 months,

Table 3: Multivariate analysis of clinical signs and symptoms possibly associated with the etiology, adjusted for age, ${ }^{*} \mathrm{OR}=$ odds ratio; ${ }^{* *} \mathrm{R}^{2}=$ coefficient of regression

\begin{tabular}{|l|l|l|l|}
\hline & $\mathrm{OR}^{*}$ & $\mathrm{p}$ & $\mathrm{R}^{2 *}$ \\
\hline $\begin{array}{l}\text { Outcome: } \\
\text { wheezing }\end{array}$ & 0.04 & 0.01 & 0.68 \\
whooping cough & 0.96 & 0.05 & \\
age & & & \\
\hline $\begin{array}{l}\text { Outcome: fever } \\
\text { whooping cough }\end{array}$ & 0.23 & 0.16 & 0.43 \\
age & 0.97 & 0.04 & \\
\hline
\end{tabular}

In the univariate analysis, cyanosis and younger age were significantly associated with BP and wheezing and fever were associated with RV. In multivariate analysis, the presence of wheezing remained associated with the respiratory viruses infections and underage associated with infection by BP ( $p=0.01$ and $p=0.05$, respectively) this model explains $68 \%$ of our results $\left(R^{2}=0.68\right)$. The presence of wheezing had positive predictive value (PPV) for viral infection of $83 \%$ and negative predictive value (NPV) of $86 \%$. The higher incidence of fever in viral infections has not remained significant in the multivariate analysis adjusted for age $\left(p=0.16 ; R^{2}=0.43\right.$ ) (Table 3 )

The leukocytes count in peripheral blood above $20.000 / \mathrm{mm}^{3}$ showed PPV for BP $36 \%$ and NPV of $66 \%$. The lymphocytes count above $15.000 / \mathrm{mm}^{3}$ had a PPV of $56 \%$ and NPV of $71 \%$.

\section{Discussion}

The preliminary results of this prospective cohort study highlight the importance of RV test on infants with suspected pertussis, since infections RV were frequent, there have been cases of co-detection with BP and RV and the classical signs of pertussis were not sensitive enough to identify the etiology of the infection.

Several previous studies have shown the importance of BP investigation in patients with viral bronchiolitis $[1,6,7]$. This study differs from the other because it drives up the need to expand the etiological diagnoses test and point the viral etiology the same age of the first dose of vaccine BP. Previous studies show that, in fact, the frames of severe pertussis requiring hospitalization occur preferentially in under two months. The immune response improves after the subsequent doses of vaccine that contribute to the reduction of the incidence of pertussis [8-10,12,13].

Respiratory virus infections more often presented with wheezing, so that wheezing had positive and negative predictive values above $80 \%$. Fever was more common in viral infections, but this association was not maintained independently when adjusted for age. The presence of post cough cyanosis was more frequent in pertussis and was present in all cases. Despite the significant difference, it is important to emphasize that about $70 \%$ of cases of viral infections also presented with cyanosis. Moreover, pertussis typical signs, as inspiratory whoop, where not significantly different between the two etiologies. In our retrospective study conducted previously, inspiratory whoop has only been described in patients with BP $(p<0.001)$ and post cough apnoea was reported in $23 \%$ of positive patients and $8 \%$ of BP with RV ( $p=0.22)$ [4].

Laboratory tests also showed limited value for the pertussis diagnosis. The leukocytes count in the peripheral blood above $20.000 / \mathrm{mm}^{3}$ had low positive and negative predictive values for $\mathrm{BP}$, as well as the lymphocytes count above $15.000 / \mathrm{mm}^{3}$. The absence of leukocytosis and lymphocytosis were better makers than other features to exclude BP, but with low NPV.

Some previous studies have called attention to the simultaneous detection of BP and RV $[3,4,14]$. Kruijssen and colleagues found co-detection of BP and other agents as RV, Mycoplasma pneumoniae and Chlamydia pneumonia in $37 \%$ of suspected cases of BP [15]. Two other previous studies analyzed the presence of respiratory viruses in children with confirmed BP infection. Moshal and colleagues showed that among 55 children positive for BP, 25 had test for VR and 5 were positive (20\% - 2 RSV and 3 influenza A virus). All co-detection occurred in children under 6 months unimmunized or partially immunized for BP [16]. In a study conducted at the Federal University of Health Sciences of Porto Alegre, among 161 cases of confirmed BP infection, $21.4 \%$ had co-detection with respiratory viruses, the most common virus were: adenovirus (40.9\%), RSV (22.7\%), parainfluenza virus type $3(22.7 \%)$, influenza B, 
Metapneumovirus, parainfluenza virus type 1 and Bocavirus [13]. The aforementioned study consistent with the results presented here, but with higher rates of co-detection with RV, which may be due to the age, and sensitivity of the laboratory tests used [17]. It is possible that the use of molecular methods for RV resulted in greater co-detection index in our study.

The small number of cases did not allow analyzing the severity of co-infection. Although it is not possible to correlate co-infection with poor clinical outcome, it is noted that two in three patients who had co-infection (one with adenovirus and one with RSV) required hospitalization in an intensive care unit and ventilatory support, taking time total hospitalization of 18 and 22 days. In the retrospective study previously conducted by the authors there was one death among the 3 patients with codetection [4]. In addition, the study of Moshal and collaborators, one patient with both infections at the same time, were admitted to the ICU and required mechanical ventilation [16].

This short communication presents preliminary results that need to be confirmed by the end of the cohort study.

\section{Conclusion}

The preliminary results of this prospective cohort suggest that RV detection as single agents was common in infants with suspected pertussis cases and also show BP and RV codetection. BP infection occurred more often in younger infants and wheezing was more common in viral infections. The typical clinical signs and symptoms of pertussis as well as laboratory tests were not suitable to differentiate etiologies. These results support the contribution of RV tests in infants hospitalized with suspected pertussis, particularly for those not fully immunized.

\section{References}

1. Nicolai A, Nenna R, Stefanelli P, Carannante A, Schiavariello C, et al. (2013) Bordetella pertussis in infants hospitalized for acute respiratory symptoms remains a concern. BMC Infect Dis 13: 526.

2. Costa LF, Yokosawa J, Mantenese OC, Oliveira TFM, Silveira HL, et al. (2006) Respiratory viruses in children younger than five years old with acute respiratory disease from 2001 to 2004 in Uberlândia, MG, Brazil. Mem Inst Oswaldo Cruz, Rio de Janeiro 101: 301-306.

3. Moreno Samos M, Amores Torres M, Pradillo Martín MC, MorenoPérez D, Cordón Martínez A, et al. (2015) Incidence and severity of pertussis in infants with a respiratory syncytial virus infection. Enferm Infecc Microbiol Clin 33: 476-479.

4. Ferronato AE, Gilio AE, Vieira SE (2013) Respiratory viral infections in infant with clinically suspected pertussis. J Pediatr (Rio J) 89: 549-553.
5. Leite D, Blanco RM, Melo LCV, Fiorio CE, Martins LM, et al. (2013) Implementation and Assessment of the Use of Real-Time PCR in Routine Diagnosis for Bordetella pertussis Detection in Brazil. Arch Pediatr Infect Dis 1: 196-202.

6. Nuolivirta K, Koponen P, He Q, Halkosalo A, Korppi M, et al. (2010) Bordetella pertussis infection is common in nonvaccinated infants admitted for bronchiolitis. Pediatr Infect Dis J 29: 1013-1050.

7. Korppi M, Hiltunen J (2007) Pertussis is common in nonvaccinated hospitalized for respiratory syncytial virus infection. Pediatr infect Dis J 26: 316-318.

8. kerr JR, Matthews RC (2000) Bordetella pertussis infection: pathogenesis, diagnosis, management, and the role of protective immunity. Eur J Clin Microbiol Infect Dis 19: 77-88.

9. Domenech de Cellès M, Magpantay FM, King AA, Rohani P (2016) The pertussis enigma: reconciling epidemiology, immunology and evolution. Proc Biol Sci 283: 1822.

10. Bardach A, Rey-Ares L, Cafferata ML, Cormick G, Romano M, et al. (2014) Systematic review and meta-analysis of respiratory syncytial virus infection epidemiology in Latin America. Rev Med Virol 24: 76-89.

11. Tozzi $A E$, Ravà L, Ciofi degli Atti ML, Salmaso S, Progetto Pertosse Working Group (2003) Clinical presentation of pertussis in unvaccinated and vaccinated children in the first six years of life. Pediatrics 112:1069-1075.

12. Ministério da saúde (2013) Secretaria de Vigilância em saúde (BR) Ministério da Saúde alerta sobre a situação epidemiológica da coqueluche no Brasil. Brasília.

13. Torres RSLA, Santos TZ, Torres RAA, Pereira VVG, Favero LSF, et al. (2015) Resurgence of pertussis at the age of vaccination: clinical, epidemiological, and molecular aspect. J Pediatr (Rio J) 91: 333-338.

14. Bellettini CV, de Oliveira AW, Tusset C, Baethgen LF, Amantéa SL, et al. (2014) Clinical, laboratorial and radiographic predictors of Bordetella pertussis infection. Rev. paul. Pediatr 32: 292-298.

15. Van Kruijssen AM, Templeton KE, Vander Plas RN, Van Doom RH, Claas EC, et al. (2007) Detection of respiratory pathogens by realtime PCR in children with clinical suspicion of pertussis. Eur J Pediatr 166: 1189-1191.

16. Moshal KL, Hodinka RL, McGowan KL (1998) Concomitant viral and Bordetella pertussis infections in infants. Pediatr Infect Dis J 17: 353-354.

17. Templeton KE, Scheltinga SA, Beersma M FC, Kroes ACM, Claas EC (2004) Rapid and sensitive method using multiplex real-time PCR for diagnosis of infections by influenza and influenza B viruses, respiratory syncytial virus, and parainfluenza viruses $1,2,3$, and 4 . J Clin Microbiol 42: 1564-1569. 